\title{
Medidas corporais de novilhos das gerações avançadas do cruzamento rotativo entre as raças Charolês e Nelore, terminados em confinamento
}

\author{
Body measurements of feedlot finished steers from advanced generations of rotational crossbreeding \\ between Charolais and Nellore breeds
}

\author{
Luís Fernando Glasenapp de Menezes ${ }^{\mathrm{I}}$ João Restle ${ }^{\mathrm{II}}$ Fernando Kuss ${ }^{\mathrm{III}}$ Ivan Luiz Brondani ${ }^{\mathrm{IV}}$ \\ Dari Celestino Alves Filho ${ }^{\mathrm{IV}}$ Jonatas Catellam $^{\mathrm{V}}$ Milene Puntel Osmari $^{\mathrm{VI}}$
}

\section{RESUMO}

Foram avaliados, durante a terminação, os efeitos da heterozigose e do grupo genético nas medidas corporais de novilhos puros (Charolês - C e Nelore - N) e mestiços da segunda (G2) (3/4C1/4N e 3/4N1/4C), da terceira (G3) (5/ $8 C 3 / 8 N$ e 5/8N3/8C) e da quarta (G4) (11/16C5/16N e 11/ $16 N 5 / 16 C)$ geração de cruzamento rotativo. Os novilhos foram confinados durante 97 dias, sendo alimentados com a mesma dieta, contendo $12,32 \%$ de proteína bruta e 2,96Mcal de energia digestível $\mathrm{kg}^{-1}$ de matéria seca, com relação volumoso:concentrado de 52:48. Os mestiços apresentaram maiores alturas de cernelha e garupa que a média dos puros tanto no início como no final do confinamento em todas as gerações do cruzamento. No entanto, os animais da G3 tiveram menor taxa de crescimento de garupa que os puros, com heterose de $-35,97 \%$. A heterose para as alturas de cernelha e garupa acompanhou a flutuação do grau de heterozigose do cruzamento, porém com diferentes magnitudes. A heterose da G2 para a G3 teve aumento de 48,18; 18,32; 55,15 e 3,20\% para as alturas de cernelha inicial e final e para a altura de garupa inicial e final, respectivamente. Dentro dos sistemas de acasalamento, os animais com predominância de Nelore apresentaram maiores alturas de cernelha e garupa que aqueles com maior predominância de Charolês. Os animais mestiços apresentaram maior perímetro torácico e comprimento inicial em todas as gerações, resultando em heteroses de 5,56; 7,73 e $5,91 \%$ e de 7,23; 8,98 e 8,99\%, respectivamente, na G2, na G3 e na G4. Todas as medidas corporais foram correlacionadas significativamente com o peso, tanto no início como no fim do confinamento.

Palavras-chave: altura, comprimento, heterose, heterozigose, perímetro torácico.

\begin{abstract}
The objective of this research was to evaluate the heterozygosis and genetic group effects on body measurements of feedlot finished steers, straightbreds (Charolais - $C$ and Nellore - N), and crossbreds from second (G2) (3/4C 1/4N and 3/4N 1/ $4 C)$, third (G3) $(5 / 8 C 3 / 8 N$ and $5 / 8 N 3 / 8 C)$ and fourth (G4) $(11 / 16 C 5 / 16 N$ and $11 / 16 N$ 5/16C) generation of rotational crossbreeding. The steers were fed during 97 days with the same diet, containing $12.32 \%$ crude protein and $2.96 \mathrm{Mcal}$ of digestible energy $\mathrm{kg}^{-1}$ of dry matter, with roughage: concentrate ratio of 52: 48. Crossbred steers showed higher withers and rump heights, at the beginning and at end of the feedlot period, in relation to straightbreds in alls generations of crossbreeding. However, G3 animals showed lower rump growth rate than the straightbreds, with the heterosis $-35.97 \%$. The heterosis for rump and withers heights followed the fluctuation of the degree of heterozygosis of the crossbreeding, however, with different magnitudes. Heterosis from G2 to G3 increased 48.18; 18.32; 55.15 and $3.20 \%$ for initial and final heights of withers and for initial and final heights of rump, respectively. Within the crossbreeding systems, animals with Nellore predominance had higher rump and withers heights than those with Charolais predominance. Crossbred animals had greater thoracic perimeter and initial body length in all crossbreeding generations, with the heterosis 5.56; 7.73 and 5.91\% and, 7.23; 8.98 and $8.99 \%$, respectively, in G2, G3 and G4. All the body measurements were significantly correlated with body weight at the beginning and at the end of the feedlot period.
\end{abstract}

Key words: height, heterosis, heterozygosis, length, thoracic perimeter.

\footnotetext{
IPrograma de Pós-graduação em Zootecnia (PPGZ), Departamento de Zootecnia, Universidade Federal de Santa Maria (UFSM), 97105-900, Santa Maria, RS, Brasil. E-mail: 1fgdm@yahoo.com.br. Autor para correspondência.

IUniversidade Federal de Goiânia (UFG), Goiânia, GO, Brasil.

IIIPrograma de Pós-graduação em Zootecnia, Universidade Federal do Rio Grande do Sul (UFRGS), Porto Alegre, RS, Brasil.

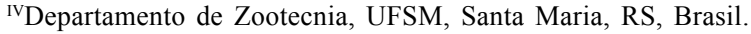

${ }^{\mathrm{v}}$ Curso de Medicina Veterinária, UFSM, Santa Maria, RS, Brasil.

${ }^{\mathrm{VI}}$ Curso de Zootecnia, UFSM, Santa Maria, RS, Brasil.
} 


\section{INTRODUÇÃO}

A maioria das avaliações de desempenho ponderal dos animais relaciona-se apenas a medidas de peso. No entanto, outras medidas relacionadas ao desenvolvimento e à estrutura corporal dos bovinos são importantes (RESTLE et al.,1981; NORTHCUTT et al., 1992; CERDÓTES et al., 2002).

NORTHCUTT et al. (1992) observaram que mensurações corporais lineares, como altura e comprimento, são mais precisas na determinação do tamanho à maturidade que o peso, pois o peso e a gordura subcutânea podem sofrer flutuações periódicas, conforme o estado nutricional dos animais, enquanto as medidas corporais lineares são mais constantes.

Estudando as medidas corporais em bovinos na idade bem jovem, CERDÓTES et al. (2002) observaram maior altura em bezerros Nelore e em mestiços com predominância de Nelore, quando comparados aos bezerros Charolês e mestiços com predominância Charolês. No entanto, não constataram diferença entre os grupos genéticos quanto ao perímetro torácico dos bezerros aos 84 dias de idade.

Os aspectos do tamanho da estrutura corporal (frame size) de bovinos de corte, definido como a proporção entre as medidas de altura e comprimento do corpo, têm sido utilizados como um critério de escolha de animais para produção de carcaças com determinados peso e graus de acabamento e qualidade (BARBOSA, 2006). Abordando as características métricas do desenvolvimento corporal, RESTLE et al. (2006) concluíram que animais altos não são desejados em sistemas de terminação em confinamento de novilhos superjovens, sendo preferidos animais compridos e, principalmente, com maior perímetro torácico. Para ROCHA et al. (2003), é impossível identificar um tamanho ideal para todas as situações de produção, citando que o tipo biológico que terá desempenho mais adequado em cada uma precisa ser identificado em adequação ao nível tecnológico e aos potenciais ecorregionais (ambiental e sócio-econômico), contribuindo para a sustentabilidade do sistema de produção a fim de que este seja competitivo e rentável.

As medidas corporais como altura, comprimento e perímetro torácico são mais constantes nas raças puras. Por outro lado, em animais mestiços, há grandes variações destas medidas em decorrência, principalmente, da diferença na composição genética dos animais. Segundo PEREIRA et al. (2000), a heterozigose tem grande efeito sobre as características de desenvolvimento ponderal. MENEZES et al. (2005) verificaram que a heterose para peso de abate de novilhos jovens acompanhou as oscilações do grau de heterozigose individual. KOGER et al. (1975) foram os que inicialmente mostraram a linearidade entre heterose e heterozigose e, segundo KOGER (1973), quanto maior o distanciamento genético maior o nível da heterose resultante.

Objetivou-se, neste experimento, avaliaremse as características de desenvolvimento corporal, assim como suas respectivas heteroses, em novilhos jovens da segunda, da terceira e da quarta geração do cruzamento alternado contínuo das raças Charolês e Nelore, terminados em confinamento.

\section{MATERIAL E MÉTODOS}

O trabalho foi realizado no setor de bovinocultura de corte do Departamento de Zootecnia da Universidade Federal de Santa Maria (UFSM).

Foram avaliados os efeitos de heterose e grupo genético nas características de desenvolvimento corporal de novilhos jovens puros (Charolês - $\mathrm{C}$ e Nelore - N) e mestiços da segunda (G2) (3/4C 1/4N e 3/ $4 \mathrm{~N} 1 / 4 \mathrm{C})$, da terceira (G3) $(5 / 8 \mathrm{C} 3 / 8 \mathrm{~N} \mathrm{e} 5 / 8 \mathrm{~N} 3 / 8 \mathrm{C})$ e da quarta (G4) (11/16C 5/16N e 11/16N 5/16C) geração de cruzamento. Foram utilizados 78 novilhos tomados ao acaso da fazenda experimental da UFSM, nascidos na mesma época de parição e mantidos sempre sob as mesmas condições de manejo e alimentação.

Os novilhos foram gerados por fêmeas puras e mestiças inseminadas com sêmen de seis touros de cada raça pura. Quatro touros de cada raça foram utilizados para o repasse na monta a campo. Os touros Charolês que geraram os novilhos Charolês foram os mesmos que geraram os novilhos $3 / 4 \mathrm{C} 1 / 4 \mathrm{~N}, 5 / 8 \mathrm{C} 3 / 8 \mathrm{~N}$ e $11 / 16 \mathrm{C} 5 / 16 \mathrm{~N}$, assim como os touros Nelore que geraram os novilhos Nelore foram os mesmos que geraram os novilhos $3 / 4 \mathrm{~N} 1 / 4 \mathrm{C}, 5 / 8 \mathrm{~N} 3 / 8 \mathrm{C}$ e $11 / 16 \mathrm{~N} \mathrm{5/}$ $16 \mathrm{C}$.

Ao início do período de terminação em confinamento, os animais apresentavam em média 20 meses de idade e $304 \mathrm{~kg}$. O período total de confinamento teve a duração de 97 dias, sendo que, nos primeiros 14 dias de confinamento, os animais foram submetidos à adaptação ao ambiente e à dieta alimentar. Esta continha $12,32 \%$ de proteína bruta (PB), $2,96 \mathrm{Mcal}$ de energia digestível e 58,30\% de fibra em detergente neutro (FDN). O volumoso, representando $52 \%$ da matéria seca total oferecida, foi constituído de silagem de milho (AG 5011). O concentrado foi composto por $93,97 \%$ de farelo de trigo, $1,5 \%$ de uréia, $3,62 \%$ de calcário calcítico e $0,9 \%$ de sal comum. Adicionada ao concentrado constava a monensina sódica, que era regulada conforme recomendação do fabricante. 
As medidas corporais foram tomadas no início e no final do experimento com o auxílio de tronco de contenção e instrumentos métricos adequados. Foram obtidas: altura do anterior ou da cernelha, correspondendo à distância da cernelha até a superfície do solo, e altura do posterior ou da garupa, correspondendo à distância do sacro até a superfície do solo, sendo estas medidas tomadas com auxílio de um esquadro; perímetro torácico, tomado com auxílio de fita métrica; e comprimento, correspondendo à distância entre a ponta inferior da espádua e a ponta do ísqueo, tomada lateralmente com auxílio de fita métrica.

A heterose de cada característica foi calculada dividindo-se a média dos mestiços dentro de cada geração pela média dos puros, sendo esse resultado subtraído de 1 e multiplicado por 100. Também foi calculada a heterose retida, em que a média de todos os mestiços foi dividida pela média dos puros, sendo esse resultado então subtraído de 1 e multiplicado por 100.

Os dados foram analisados através da análise de variância e as médias foram comparadas pelo teste t (SAS, 1997), utilizando-se o seguinte modelo estatístico:

$$
\mathrm{Y}_{\mathrm{ijk}}=\mu+\mathrm{IV}_{\mathrm{k}}+\mathrm{SA}_{\mathrm{i}}+\mathrm{GG}_{\mathrm{j}}\left(\mathrm{SA}_{\mathrm{i}}\right)+\mathrm{E}_{\mathrm{ij \textrm {j }}} \text {; }
$$

em que $\mathrm{Y}_{\mathrm{ij}}$ refere-se a variáveis dependentes; $\mu$, à média de todas as observações; $\mathrm{IV}_{\mathrm{k}}$, ao efeito da idade da mãe dos novilhos de índice k; SA, ao efeito do sistema de acasalamento i, sendo 1 (puros), 2 (mestiços da G2), 3 (mestiços da G3) e 4 (mestiços da G4); $\mathrm{GG}_{\mathrm{j}}\left(\mathrm{SA}_{\mathrm{i}}\right)$, ao efeito do grupo genético de índice $\mathrm{j}$, sendo $j=1$ - Charolês - e 2 - Nelore - dentro do SA $1 ; 1$ - 3/4C 1/4N - e 2 - 3/4N 1/4C - dentro do SA 2 ; 1 - 5/8C $3 / 8 \mathrm{~N}-\mathrm{e} 2-5 / 8 \mathrm{~N} 3 / 8 \mathrm{C}$ - dentro do SA $3 ; 1$ - 11/16C 5/16N e 2 - 11/16N 5/16C - dentro do SA 4; e $\mathrm{E}_{\mathrm{ijk}}$, ao efeito aleatório residual.

\section{RESULTADOS E DISCUSSÕES}

Na tabela 1, estão expressas as médias e heteroses para as alturas de cernelha e garupa iniciais e finais, assim como os ganhos de altura durante o período de confinamento.

Os mestiços apresentaram maiores alturas que a média dos puros tanto no início como no final do confinamento em todas as gerações do cruzamento, sendo a heterose significativa em todas as gerações de cruzamento. A heterose para as medidas de altura acompanhou o grau de heterozigose do cruzamento, porém com diferentes magnitudes. A heterozigose é de $50 \%$ na G2, 75\% na G3, representando aumento de $50 \%$, e de $62,5 \%$ na G4, representando queda de $17 \%$ da G3 para a G4. A heterose da G2 para a G3 teve aumento de 48,$18 ; 18,32 ; 55,15$ e $3,20 \%$ para a altura de cernelha inicial e final e para a altura de garupa inicial e final,

Tabela 1 - Médias, erros-padrão e heterose para as alturas de cernelha e garupa iniciais e finais, assim como o ganho em altura de cernelha e garupa de novilhos, de acordo com o grupo genético.

\begin{tabular}{|c|c|c|c|c|c|c|}
\hline \multirow{2}{*}{ Grupo genético } & \multicolumn{6}{|c|}{ Altura, $\mathrm{cm}$} \\
\hline & Cernelha inicial & Cernelha final & Ganho em cernelha & Garupa inicial & Garupa final & Ganho em garupa \\
\hline Charolês (C) & $115,7 \pm 2,2^{b}$ & $122,0 \pm 2,1^{b}$ & $6,33 \pm 1,0$ & $121,3 \pm 2,4^{b}$ & $128,5 \pm 2,1^{b}$ & $7,17 \pm 1,7$ \\
\hline Nelore (N) & $125,0 \pm 1,4^{\mathrm{a}}$ & $129,7 \pm 1,4^{\mathrm{a}}$ & $4,67 \pm 0,7$ & $131,9 \pm 1,5^{\mathrm{a}}$ & $136,1 \pm 1,9^{\mathrm{a}}$ & $4,27 \pm 1,1$ \\
\hline Média puros & $120,3 \pm 1,3$ & $125,8 \pm 1,3$ & $5,50 \pm 0,6$ & $126,6 \pm 1,4$ & $132,3 \pm 1,7$ & $5,72 \pm 1,0$ \\
\hline $3 / 4 \mathrm{C} 1 / 4 \mathrm{~N}$ & $121,7 \pm 2,2^{b}$ & $128,8 \pm 2,1^{b}$ & $7,17 \pm 1,0$ & $127,7 \pm 2,4^{b}$ & $135,0 \pm 3,0$ & $7,33 \pm 1,7$ \\
\hline $3 / 4 \mathrm{~N}^{1 / 4} \mathrm{C}$ & $129,6 \pm 1,8^{\mathrm{a}}$ & $136,1 \pm 1,8^{\mathrm{a}}$ & $6,56 \pm 0,8$ & $136,4 \pm 2,0^{\mathrm{a}}$ & $142,0 \pm 2,4$ & $5,56 \pm 1,4$ \\
\hline Média G2 & $125,6 \pm 1,4$ & $132,5 \pm 1,4$ & $6,86 \pm 0,7$ & $132,1 \pm 1,5$ & $138,5 \pm 1,9$ & $6,44 \pm 1,1$ \\
\hline Heterose G2 & $4,40 * *$ & $5,24 *$ & 24,82 & $4,30 * *$ & $4,69 * *$ & 12,67 \\
\hline $5 / 8 \mathrm{C} 3 / 8 \mathrm{~N}$ & $126,0 \pm 1,7$ & $131,2 \pm 1,4^{\mathrm{b}}$ & $5,17 \pm 0,8$ & $132,8 \pm 1,7$ & $136,8 \pm 1,9$ & $4,00 \pm 1,1$ \\
\hline $5 / 8 \mathrm{~N} 3 / 8 \mathrm{C}$ & $130,4 \pm 1,5$ & $136,1 \pm 1,3^{\mathrm{a}}$ & $5,33 \pm 0,7$ & $137,3 \pm 1,5$ & $140,6 \pm 1,7$ & $3,33 \pm 1,0$ \\
\hline Média G3 & $128,2 \pm 1,1$ & $133,7 \pm 0,9$ & $5,25 \pm 0,5$ & $135,1 \pm 1,1$ & $138,7 \pm 1,3$ & $3,67 \pm 0,7$ \\
\hline Heterose G3 & $6,52 *$ & $6,20^{*}$ & $-4,55$ & $6,67^{*}$ & $4,84^{*}$ & $-35,93 * * *$ \\
\hline $11 / 16 \mathrm{C} 5 / 16 \mathrm{~N}$ & $127,1 \pm 1,7$ & $132,2 \pm 1,6$ & $5,11 \pm 0,9$ & $134,4 \pm 1,8$ & $138,2 \pm 2,2$ & $3,80 \pm 1,4$ \\
\hline $11 / 16 \mathrm{~N} 5 / 16 \mathrm{C}$ & $127,8 \pm 2,1$ & $133,8 \pm 2,0$ & $6,00 \pm 1,2$ & $133,2 \pm 2,2$ & $136,7 \pm 2,7$ & $3,50 \pm 1,8$ \\
\hline Média G4 & $127,5 \pm 1,3$ & $133,0 \pm 1,3$ & $5,56 \pm 0,7$ & $133,8 \pm 1,4$ & $137,4 \pm 1,7$ & $3,64 \pm 1,1$ \\
\hline Heterose G4 & $5,90 *$ & $5,68^{*}$ & 1,00 & $5,69 *$ & $3,89 * *$ & $-36,19$ \\
\hline Heterose retida & 5,61 & 5,71 & 7,09 & 5,56 & 4,47 & $-19,81$ \\
\hline Diferença mestiços e C, \% & $9,85^{*}$ & $9,04 *$ & $-6,95$ & $10,17 *$ & $7,56^{*}$ & $-36,03 * * *$ \\
\hline Diferença mestiços e N, \% & 1,68 & $2,57 * *$ & 26,12 & 1,31 & 1,56 & 7,42 \\
\hline
\end{tabular}

$* * * \mathrm{P}<0,01 * * \mathrm{P}<0,05 * \mathrm{P}<0,10$ 
respectivamente. Já da G3 para a G4, houve queda das heteroses de 10,$50 ; 9,15 ; 17,22$ e $24,42 \%$, na mesma ordem citada anteriormente. Em seu estudo, KOGER et al. (1975) mostraram a linearidade entre heterozigose e heterose.

Observa-se na tabela 1 que a heterose para ganho em altura de cernelha e garupa não foi significativa, com exceção para o ganho de altura na garupa da G3, onde a heterose foi negativa.

Comparando-se através de análise de contraste as medidas dos animais mestiços com as do Charolês puro, observa-se que as medidas de altura foram maiores nos mestiços. No entanto, a diferença entre as medidas inicial e final decresceu, sendo mais evidente e significativa na altura de garupa. Isto indica que os mestiços estavam desacelerando o desenvolvimento em altura frente ao Charolês. Esta desaceleração no desenvolvimento dos mestiços também foi verificada por MENEZES \& RESTLE (2005) ao avaliarem os pesos dos mesmos animais no início e final do confinamento, em que a diferença de $16,39 \%$ no peso inicial a favor dos mestiços em relação ao Charolês decresceu para 5,6\% no final.

Ao se compararem as medidas de altura dos mestiços com as do Nelore puro, constata-se que a diferença a favor dos mestiços foi positiva, embora tenha sido significativa apenas na altura final da cernelha, indicando que os mestiços estavam aumentando o desenvolvimento frente ao Nelore puro. No entanto, MENEZES \& RESTLE (2005) verificaram que a diferença de $32,46 \%$ no peso inicial a favor dos mestiços decresceu levemente no final do confinamento para $28,93 \%$, indicando que, além do crescimento da estrutura corporal, outros fatores, como a deposição de gordura, influenciam o peso corporal.

Novilhos Nelore foram mais altos que os Charolês, no início do confinamento, na cernelha (8\%) e na garupa (8,7\%) e no final (6 e $6 \%$, respectivamente), embora os seus pesos inicial $(241,10$ versus $274,40 \mathrm{~kg})$ e final $(330,10$ versus $403,20 \mathrm{~kg})$ tenham sido menores. Novilhos mestiços de todas as gerações de cruzamento também foram mais altos que o Charolês. Estes resultados indicam que o Nelore apresenta acentuado efeito genético aditivo para a característica altura. Esta afirmação fica evidente pela análise de contrastes, segundo o qual os novilhos mestiços com maior predominância de Nelore no genótipo apresentaram maior $(\mathrm{P}<0,05)$ altura do que os novilhos com maior predominância de Charolês. Estudando as medidas corporais em bovinos de mais tenra idade, CERDÓTES et al. (2002) observaram maior altura aos 84 dias de idade em bezerros Nelore e em mestiços com predominância de Nelore, quando comparados aos bezerros Charolês e mestiços com predominância Charolês.

As médias e heteroses para os perímetros torácicos inicial e final, o ganho em perímetro torácico, os comprimentos inicial e final e o ganho em comprimento dos novilhos de acordo com o grupo genético estão apresentadas na tabela 2. Os animais mestiços apresentaram maior perímetro torácico e comprimento inicial em todas as gerações, resultando em heteroses de 5,56; 7,73 e 5,91\% e de 7,23; 8,98 e $8,99 \%$, respectivamente, na G2, na G3 e na G4. No entanto, ao final do período de confinamento, a heterose para essas medidas deixou de ser significa na G2, sendo na G3 e na G4 de 2,85 e 3,39\%, respectivamente, para o perímetro torácico, e de 4,95 e 5,13\%, respectivamente, para o comprimento final. Observa-se que as diferenças entre os animais puros e os mestiços diminuíram no final do período de confinamento. Isto se deve ao maior ganho nestas medidas apresentadas pelos puros, o que resultou em heterose negativa em todas as gerações de cruzamento, sendo significativa na G2 e na $\mathrm{G} 3$, de $-37,08$ e $-37,45 \%$, respectivamente, para o ganho em perímetro torácico e, $-39,74$ e $-31,67 \%$, respectivamente, para o ganho em comprimento. A quarta geração do cruzamento não diferiu dos animais puros nesses parâmetros. Essa desaceleração no desenvolvimento dos animais mestiços, durante a terminação, deve-se ao fato desses apresentarem grau de maturidade mais precoce em relação aos puros, o que pode ser constatado em todas as características avaliadas no presente estudo, inclusive no peso avaliado por MENEZES \& RESTLE (2005). Esses autores observaram que o estado corporal, que reflete a deposição da gordura subcutânea, foi superior nos mestiços das três gerações em relação aos puros, tanto no início como no final do período de confinamento, o que é mais um indicativo da maior precocidade dos mestiços. Dos três tecidos, ósseo, muscular e adiposo, é o último o que tem a sua deposição intensificada à medida que o animal atinge a maturidade (BERG \& BUTTERFIELD, 1976).

Segundo ROCHA et al. (2003), o perímetro torácico tem sido considerado a medida linear de maior precisão na determinação do crescimento muscular e o comprimento corporal, a de menor precisão. Os mesmos autores observaram que o comprimento e a altura variam em função de crescimento do esqueleto, atingindo um limiar à maturidade, sendo o perímetro torácico em função do crescimento muscular.

Para as variáveis apresentadas na tabela 2, não houve diferença significativa entre os novilhos puros nem entre os mestiços dentro de cada geração de cruzamento. CERDÓTES et al. (2002) também não 
Medidas corporais de novilhos das gerações avançadas do cruzamento rotativo entre as raças Charolês e Nelore...

Tabela 2 - Médias, erros-padrão e heteroses para perímetros torácicos inicial e final, ganho em perímetro torácico (GPtorax), comprimentos inicial e final e ganho em comprimento de novilhos, de acordo com o grupo genético.

\begin{tabular}{|c|c|c|c|c|c|c|}
\hline Grupo genético & $\begin{array}{l}\text { Perímetro } \\
\text { torácico inicial }\end{array}$ & $\begin{array}{l}\text { Perímetro } \\
\text { torácico final }\end{array}$ & GPtorax & Comp. inicial & Comp. final & Ganho em comp. \\
\hline Charolês (C) & $159,7 \pm 3,5$ & $179,5 \pm 3,7$ & $19,83 \pm 2,3$ & $123,5 \pm 3,6$ & $136,2 \pm 3,4$ & $12,67 \pm 2,9$ \\
\hline Nelore $(\mathrm{N})$ & $153,3 \pm 2,2$ & $171,2 \pm 2,3$ & $17,87 \pm 1,5$ & $117,0 \pm 2,3$ & $130,6 \pm 2,2$ & $13,60 \pm 1,8$ \\
\hline Média puros & $156,5 \pm 2,1$ & $175,4 \pm 2,2$ & $18,85 \pm 1,4$ & $120,3 \pm 2,1$ & $133,40 \pm 2,0$ & $13,13 \pm 1,7$ \\
\hline $3 / 4 \mathrm{C} 1 / 4 \mathrm{~N}$ & $163,7 \pm 3,5$ & $176,2 \pm 3,0$ & $12,50 \pm 2,3$ & $128,0 \pm 3,6$ & $137,53,4$ & $9,50 \pm 2,9$ \\
\hline $3 / 4 \mathrm{~N}^{1 / 4 \mathrm{C}}$ & $166,7 \pm 2,8$ & $177,9 \pm 3,7$ & $11,22 \pm 1,9$ & $129,9 \pm 2,9$ & $136,2 \pm 2,8$ & $6,33 \pm 2,4$ \\
\hline Média G2 & $165,2 \pm 2,2$ & $177,0 \pm 2,4$ & $11,86 \pm 1,5$ & $128,9 \pm 2,3$ & $136,9 \pm 2,2$ & $7,92 \pm 1,9$ \\
\hline Heterose G2 & $5,56^{*}$ & 0,97 & $-37,08^{*}$ & $7,23 *$ & 2,59 & $-39,74 * *$ \\
\hline $5 / 8 \mathrm{C} 3 / 8 \mathrm{~N}$ & $167,1 \pm 2,3$ & $179,2 \pm 2,3$ & $12,08 \pm 1,7$ & $132,2 \pm 2,6$ & $139,9 \pm 2,2$ & $7,75 \pm 2,1$ \\
\hline $5 / 8 \mathrm{~N} \mathrm{3/8C}$ & $170,1 \pm 2,0$ & $181,5 \pm 2,1$ & $11,50 \pm 1,5$ & $129,9 \pm 2,3$ & $140,1 \pm 2,0$ & $10,20 \pm 1,9$ \\
\hline Média G3 & $168,6 \pm 1,5$ & $180,4 \pm 1,5$ & $11,78 \pm 1,1$ & $131,0 \pm 1,7$ & $140,0 \pm 1,5$ & $8,98 \pm 1,4$ \\
\hline Heterose G3 & $7,73 *$ & $2,85 * *$ & $-37,45^{*}$ & $8,98^{*}$ & $4,95^{*}$ & $-31,67 * * *$ \\
\hline $11 / 16 \mathrm{C} 5 / 16 \mathrm{~N}$ & $167,7 \pm 3,0$ & $184,1 \pm 3,2$ & $16,44 \pm 1,9$ & $135,1 \pm 2,6$ & $142,8 \pm 2,4$ & $7,67 \pm 2,4$ \\
\hline $11 / 16 \mathrm{~N} 5 / 16 \mathrm{C}$ & $163,8 \pm 3,6$ & $178,5 \pm 4,0$ & $14,67 \pm 2,3$ & $127,0 \pm 3,2$ & $137,7 \pm 3,0$ & $10,67 \pm 2,9$ \\
\hline Média G4 & $165,8 \pm 2,4$ & $181,3 \pm 2,6$ & $15,56 \pm 1,5$ & $131,1 \pm 2,1$ & $140,2 \pm 1,9$ & $9,17 \pm 1,9$ \\
\hline Heterose G4 & $5,91 *$ & $3,39 * * *$ & $-17,48$ & $8,99 *$ & $5,13 * *$ & $-30,19$ \\
\hline Heterose retida & 6,40 & 2,40 & $-30,67$ & 8,40 & 4,22 & $-33,87$ \\
\hline Diferença mestiços e C, \% & $4,27 * *$ & 0,04 & $-34,10^{*}$ & $5,55 * * *$ & 2,08 & $-31,44$ \\
\hline Diferença mestiços e N, \% & $8,62 *$ & $4,89 *$ & $-26,87^{*}$ & $11,41^{*}$ & $6,46^{*}$ & $-36,13 *$ \\
\hline
\end{tabular}

$* * * \mathrm{P}<0,01 * * \mathrm{P}<0,05 * \mathrm{P}<0,10$

observaram diferença significativa no perímetro torácico de bezerros Charolês e Nelore aos 84 dias de idade.

Comparando-se os mestiços com o Charolês, através da análise de contraste, verifica-se que os mestiços foram superiores no perímetro torácico e no comprimento inicial, deixando assim, de ser significativa no final do confinamento. Com relação ao Nelore, os mestiços foram superiores nas duas medidas no início e, embora a diferença tenha decrescido no final, esta ainda se manteve significativa.

$\mathrm{Na}$ tabela 3, constam as correlações fenotípicas entre as características, separadamente para animais com predominância Charolês ou Nelore no genótipo. Todas as medidas foram correlacionadas significativamente com o peso, tanto no início como no fim do confinamento. Nos novilhos com

Tabela 3 - Coeficientes de correlação de Pearson acima da diagonal, entre as variáveis pesos inicial (PI) e final (PF), ganho de peso médio diário (GMD), alturas de cernelha inicial (AlCerI) e final (AlCerF), alturas de garupa inicial (AltGarI) e final (AlGarf), perímetros torácico inicial (PerTorI) e final (PerTorF), comprimentos inicial (CompI) e final (CompF) de novilhos com predominância racial Nelore (acima da diagonal) e com predominância de sangue Charolês (abaixo da diagonal).

\begin{tabular}{|c|c|c|c|c|c|c|c|c|c|c|c|}
\hline & PI & $\mathrm{PF}$ & GMD & AltCerI & AltCerf & AltGarI & AltGarF & PerTorI & PerTorF & CompI & CompF \\
\hline PI & & $0,99 *$ & $0,70^{*}$ & $0,83^{*}$ & $0,85^{*}$ & $0,76^{*}$ & $0,74^{*}$ & $0,93^{*}$ & $0,86^{*}$ & $0,82 *$ & $0,81 *$ \\
\hline $\mathrm{PF}$ & $0,95 * *$ & & $0,80^{*}$ & $0,82 *$ & $0,86^{*}$ & $0,77^{*}$ & $0,75^{*}$ & $0,92 *$ & $0,84^{*}$ & $0,83^{*}$ & $0,82 *$ \\
\hline GMD & 0,23 & $0,65 * *$ & & $0,58 * *$ & $0,71 * *$ & $0,59 * *$ & $0,60 * *$ & $0,67 * *$ & $0,57 * *$ & $0,69 * *$ & $0,64 * *$ \\
\hline AlCerI & $0,82 * *$ & $0,80 * *$ & 0,24 & & $0,88 * *$ & $0,88 * *$ & $0,85^{* *}$ & $0,73^{* *}$ & $0,74 * *$ & $0,79 * *$ & $0,76^{* *}$ \\
\hline AlCerF & $0,77 * *$ & $0,73 * *$ & 0,17 & $0,90 * *$ & & $0,82 * *$ & $0,85^{* *}$ & $0,74 * *$ & $0,76^{* *}$ & $0,84 * *$ & $0,84 * *$ \\
\hline AltGarI & $0,73^{* *}$ & $0,73 * *$ & 0,28 & $0,83^{* *}$ & $0,83 * *$ & & $0,84 * *$ & $0,65^{* *}$ & $0,67 * *$ & $0,80 * *$ & $0,70 * *$ \\
\hline AltGarf & $0,79^{* *}$ & $0,77 * *$ & 0,24 & $0,84 * *$ & $0,92 * *$ & $0,88^{* *}$ & & $0,64 * *$ & $0,74 * *$ & $0,76^{* *}$ & $0,79 * *$ \\
\hline PerTorI & $0,82 * *$ & $0,80 * *$ & 0,23 & $0,66^{* *}$ & $0,61 * *$ & $0,65 * *$ & $0,66^{* *}$ & & $0,85^{* *}$ & $0,69 * *$ & $0,75 * *$ \\
\hline PerTorF & $0,80 * *$ & $0,82 * *$ & $0,39^{*}$ & $0,52 * *$ & $0,46^{* *}$ & $0,49 * *$ & $0,51 * *$ & $0,75 * *$ & & $0,69 * *$ & $0,86^{* *}$ \\
\hline CompI & $0,78 * *$ & $0,76^{* *}$ & 0,23 & $0,76^{* *}$ & $0,61 * *$ & $0,67 * *$ & $0,64 * *$ & $0,73 * *$ & $0,63 * *$ & & $0,75^{* *}$ \\
\hline CompF & $0,75 \%$ & $0,80 * *$ & $0,43 *$ & $0,71 * *$ & $0,66^{* *}$ & $0,66 * *$ & $0,67^{* *}$ & $0,77 * *$ & $0,63 * *$ & $0,77 * *$ & \\
\hline
\end{tabular}

$* \mathrm{P}<0,01$.

$* * \mathrm{P}<0,05$.

Ciência Rural, v.38, n.3, mai-jun, 2008. 
predominância Nelore, o peso inicial esteve mais bem correlacionado com o perímetro torácico inicial $(0,93) \mathrm{e}$ o peso final com altura de cernelha final $(0,86)$. Nos novilhos com predominância Charolês, o peso inicial apresentou correlação mais elevada com o perímetro torácico $(0,82)$ e as alturas de cernelha $(0,82)$ iniciais e o peso final com o perímetro torácico final $(0,82)$. RESTLE et al. (2006), trabalhando com novilhos superjovens, constataram que a medida mais bem correlacionada com o peso corporal foi o perímetro torácico. Em outro estudo, CYRILLO et al. (2001) observaram correlação fenotípica de 0,86 entre o perímetro torácico e o peso aos 378 dias de idade.

RESTLE et al. (2006), trabalhando com bovinos superjovens, concluíram que animais altos não são desejáveis em sistemas de terminação em confinamento. Porém, no presente estudo, com animais jovens, as alturas, tanto de cernelha como de garupa, apresentaram boas correlações com o peso final dos animais, tanto naqueles de predominância Nelore como nos de predominância Charolês.

Apesar de a grande maioria das medidas corporais apresentarem boa correlação com o peso dos animais, MOHIUDDIN (1993) alerta que as correlações fenotípicas altas e positivas entre características não necessariamente significam que a seleção para uma característica levará ao melhoramento da outra, devido ao fato de a correlação fenotípica não ser sempre uma estimativa confiável da relação genética existente entre as características. No entanto, CYRILLO et al. (2001) também mediram as correlações genéticas entre o peso padronizado aos 378 dias de idade e as medidas corporais, encontrando, na sua maioria, valores considerados entre medianos e altos, indicando que genes que determinam a manifestação do peso de animais Nelore são também, em parte, responsáveis pela manifestação de medidas corporais e perímetro torácico.

Nos novilhos com predominância Charolês, as correlações fenotípicas entre as medidas corporais e o ganho de peso médio diário durante a terminação, embora significativas, foram de baixa magnitude e significativas $(\mathrm{P}<0,05)$ apenas para perímetro torácico e comprimento finais. Por outro lado, nos novilhos com predominância Nelore, as correlações entre as medidas corporais e o ganho de peso médio diário durante a terminação foram de magnitude elevada e altamente significativas $(\mathrm{P}<0,01)$ (Tabela 3$)$.

\section{CONCLUSÕES}

Novilhos mestiços do cruzamento rotativo entre as raças Charolês e Nelore apresentam maior tamanho corporal que os animais puros, apresentando altos valores de heterose. Já na comparação dentro das gerações do cruzamento, os novilhos Nelore e mestiços com predominância de sangue Nelore apresentam maior altura em relação aos novilhos Charolês e mestiços com predominância de sangue Charolês, respectivamente.

As medidas corporais apresentam altas correlações com o peso corporal, sendo bons indicativos de desenvolvimento ponderal. Além disso, animais com predominância de sangue Nelore que apresentam maior altura têm maior ganho de peso médio diário.

\section{AGRADECIMENTOS}

À Coordenação de Aperfeiçoamento de Pessoal de Nível Superior (CAPES), pelas bolsas de Menezes e Alves Filho, ao Conselho Nacional de Desenvolvimento Científico e Tecnológico $(\mathrm{CNPq})$, pelas bolsas concedidas a Restle, Kuss e Brondani e a Fundação de Amparo à Pesquisa do Estado do Ri Grande do Sul (FAPERGS), pela concessão de bolsa a Osmar.

\section{REFERÊNCIAS}

BARBOSA, P.F. Tamanho da estrutura corporal e desempenho produtivo de bovinos de corte. In: REUNIÃO ANUAL DA SOCIEDADE BRASILEIRA DE ZOOTECNIA, 43., 2006, Goiania, GO. Anais de Simpósios... Goiania: Sociedade Brasileira de Teconologia, 2006. CD ROM.

BERG, R.T.; BUTTERFIELD, R.M. New concepts of cattle growth. Sydney: Sydney University, 1976. 240p.

CERDÓTES, L. et al. Medidas corporais e desempenho do nascimento aos 84 dias de idade de bezerros Charolês, Nelore e mestiços desmamados aos 42 ou 63 dias de idade. In: REUNIÃO ANUAL DA SOCIEDADE BRASILEIRA DE ZOOTECNIA, 39., 2002, Recife, PE. Anais... Recife: Sociedade Brasileira de Zootecnia, 2002. CD ROM.

CYRILLO, J.N.S.G. et al. Estimativas de tendências e parâmetros genéticos do peso padronizado aos 378 dias de idade, medidas corporais e perímetro escrotal de machos Nelore de Sertãozinho, SP. Revista Brasileira de Zootecnia, v.30, n.1, p.56-65, 2001 .

KOGER, M. Summary. In: KOGER, M. et al. Crossbreeding beef cattle. Series 2. Gainesville: University of Florida, 1973. p.434-453.

KOGER, M. et al. Heterosis effects on weaning performance of Brahman-Shorthorn calves. Journal of Animal Science, v.40, n.5, p.826-833, 1975.

MENEZES, L.F.G.; RESTLE, J. Desempenho de novilhos de gerações avançadas do cruzamento alternado entre as raças charolês e nelore, terminados em confinamento. Revista Brasileira de Zootecnia, v.34, n.6, p.1927-1937, 2005. 
MENEZES, L.F.G. et al. Características da carcaça de novilhos de gerações avançadas do cruzamento alternado entre as raças charolês e nelore, terminados em confinamento. Revista Brasileira de Zootecnia, v.34, n.3, p.934-945, 2005.

MOHIUDDIN, G. Estimates of genetic and phenotypic parameters of some performance traits in beef cattle. Animal Breeding Abstract, v.56, n.3, p.155-167, 1993

NORTHCUTT, S.L. et al. Adjusting weight for body condition score in Angus cows. Journal of Animal Science, v.70, n.5, p.1342-1345, 1992.

PEREIRA, L.P. et al. Desenvolvimento ponderal de bovinos de corte de diferentes grupos genéticos de Charolês x Nelore inteiros ou castrados aos oito meses. Ciência Rural, v.30, n.6, p.1033-1039, 2000
RESTLE, J. et al. Silagem de diferentes hibrídos de milho para produção de novilhos superjovens. Revista Brasileira de Zootecnia, v.35, n.5, p.2066-2076, 2006.

RESTLE, J. et al. Correlations between measurements, performance and carcass characteristics of show steers. Journal of Animal Science, v.53, n.60, p.25, 1981. (Abstract, supplement 1).

ROCHA, E.D. et al. Tamanho de vacas Nelore adultas e seus efeitos no sistema de produção de gado de corte. Arquivos Brasileiros de Medicina Veterinária e Zootecnia, v.55, n.4, p.474-479, 2003.

SAS, Institute Inc. SAS'S user's guide. SAS for Windows. Carry, 1997. 1052p. 